\title{
Analysing Students' Creativity in Integrating GeoGebra Applets in Solving Geometrical Problems
}

\author{
Emiliya VELIKOVA, Magdalena PETKOVA \\ Department of Mathematics, Faculty of Natural Sciences and Education \\ University of Ruse Angel Kanchev \\ 8 Studentska Str., 7017 Ruse, Bulgaria \\ evelikova@uni-ruse.bg, maggiepetkovalicloud.com
}

\begin{abstract}
The challenges facing the economy and technologies determine the needs of the labor market for creative professionals, competent specialists, easily adaptive to the technologically changing information environment. Universities are confronted with the main task to experiment and to discover new opportunities for stimulating student creativity, for teaching and learning for mastering specific knowledge, for developing skills and competencies as a key element in their preparation for professional growth.

The authors' research investigates the creative environment for teaching and learning of students (future Mathematics and Informatics teachers in high schools), namely the developing and integrating of GeoGebra applets for solving geometric problems. The opportunities which the attractive GeoGebra software provides for training in Mathematics are used in the experimental survey. Quantitative and qualitative analyses of the results are presented.
\end{abstract}

Keywords: students' creativity, creative product, integrating GeoGebra applets, geometrical problems

\section{Introduction}

Higher education aims to train competent professionals for the labor market who are easily adaptive to the technologically changing information society. On one hand, this requires to search for new pedagogical approaches and good practices which support the training and learning aimed at acquiring specific knowledge; for forming and developing of skills and competences for innovative use of the information and computer technologies; for stimulating the human intellect and creativity; for assessing the didactical opportunities for creative acquisition of knowledge and skills, and for enhancing research (Georgieva, 2001, p. 25). On the other hand, what is needed is scientific and experimental research aimed at finding new possibilities for stimulating the creative abilities of students.

The study of creative learning and innovative teaching of Cachia et al. (2010, p. 51) supports these conclusions. The development of an experimental learning environment that provides opportunities for enhancing the creative potential of students, future 
teachers of mathematics and informatics, enables the finding of ways for their effective job-oriented pedagogical preparation. In the near future people without a minimum knowledge about technology will have serious problems to develop their professional career (Bilbao et al., 2017). A modern learning environment can be developed by using innovative tools and training methods (Petkova, 2016; Kubilinskiene et al., 2016). Training students by using the GeoGebra software responds to the ideas and recommendations of the European Parliament and the Council for developing eight Key Competences which include Mathematical Competence and Basic Competences in Science and Technology, and Digital Competence (WEBa). This dynamic mathematics software brings together geometry, algebra, spreadsheets, graphing, statistics and calculus in one easy-to-use package. The students can use it to create mathematical objects, displayed in two or more representations, which are dynamically linked. It supports STEM education and innovations in teaching and learning worldwide (WEBb). GeoGebra is a rapidly expanding community of millions of users located in just about every country. The GeoGebra Institute of Ruse (GGIR) at the University of Ruse was established in 2011 as part of the global network of more than 150 GeoGebra Institutes (WEBc).

The researches on mathematics training with GeoGebra show that the GeoGebra environment: 1) supports deeply understanding the problems and methods for creating or solving problems (Petkova and Velikova, 2015a; Villarreal and Borba, 2010); 2) stimulates creativity among the students and the problems, which they created, have creative character (Petkova and Velikova, 2015a); 3) has a positive impact on the students' achievements (Arbain and Shukor, 2015; Aizikovitsh-Udi and Radakovic, 2012; Saha et al., 2010); 4) improves and enhances students' knowledge, spatial visualisation ability and critical, creative and innovative thinking (Haciomeroglu, 2011; Kim and Md-Ali, 2017). These are some of the reasons that mathematics teachers use GeoGebra in secondary/high schools. A pilot research of mathematics learning by GeoGebra visualisation and simulation by 16 trainers showed that: 1) integrating GeoGebra applets in solving problems is highly useful in teaching $(100 \%)$; 2) mathematics teachers are prepared to use GeoGebra $(94 \%)$; 3) they will use the newly-acquired knowledge and skills in the future $(81 \%)$; 4) they expressed the desire to acquire further knowledge and skills up to the level of integrating complex GeoGebra applets (Petkova, 2011). The most important factors affecting mathematics teachers in primary education, for example in Lithuania, to utilise GeoGebra and learning objects prepared by it are (Žilinskienè and Demirbilek, 2015, p. 136): 1) GeoGebra tools are free of charge; 2) willingness to utilize learning objects created using GeoGebra - it is strongly depending on how they are created and also are related to the teachers' level of expertise in mathematics.

The didactical situations that include GeoGebra/unguided tasks support students' mathematical problem solving and creative reasoning more than didactical situations with guided tasks (Olsson, 2017).

Designing tasks fostering the synergy of visualization, reasoning abilities and constructions in GeoGebra environment and it is of crucial importance for the effective teaching of geometry (Or, 2013).

Therefore, motivating future teachers to creatively use GeoGebra by integrating applets in didactical situations during a problem-solving process is a key element of their job-oriented methodological training. 


\section{Method}

Main goals of the research: to establish conditions for learning and training which stimulate the students' creativity in integrating GeoGebra applets in solving geometrical problems and to analyse the creativity-oriented qualities of the newly-created products.

Other goals: to enable the students to learn main GeoGebra algorithms for creating applets; to develop their skills for identifying the relevant features of GeoGebra for visualising and interpreting the solution of the problem, according to the educational tasks at hand.

Participants in the research: 52 university students, future teachers of mathematics and informatics, who studied successfully subjects such as Analytic Geometry, Mathematical analysis, School geometry, Visual programming, and other related subjects.

Creative environment. Creativity is a significant pillar of society already today, but will likely become even more important in the future due to technological advancements (Bennevall, 2016). Creativity is an intersection of four kinds of clusters: creative personality, creative environment, creative process and creative product (Velikova, 2008 , p. 331). Creativity is an utmost form of human activity which produces original, new, unexpected, appropriate and useful products that are ,publicly” and ,individually” meaningful (Desev, 1999; Stenberg and Lubart, 1999). The mathematical creativity at school level is the process that results in unusual (novel) and/or insightful solutions to given/analogous problems; the formulation of new questions and/or possibilities that allow an old problem to be regarded from a new angle (Liljedahl and Sriraman, 2006). A higher level of mathematical creativity is reached when the students have an opportunity to create and test their own mathematical models (Hohenwarter et al., 2009; Martinovic and Manizade, 2014; Freiman and Tassel, 2018). The creative product is an original solution to an existing problem and it changes the methods, traditions, and viewpoints (Velikova, 2002). The students' creative product is a new one both for the student and for the target audience. It can be the application of an idea already developed in a new way or finding new application areas for well-known methods and settings, which are valuable for the student himself at the moment of their creation, rather than for the future society (Krutetskii, 1968; Velikova, 2008).

The creative environment which was established during one academic year (60 hours) aimed: 1) to motivate the students for independent/joint creativity; 2) to establish conditions for acquiring knowledge, skills, and competences for creativity in a specific interest field of the trainee; 3) to support the creativity of the student; 4) to bring satisfaction; 5) to take into consideration the interests, the abilities, the tempo and style of the student's performance; 6) to provide a suitable atmosphere for freely generating, proposing, discussing, and refining of ideas.

Training Content. There were used 12 problems from different geometrical topics from the high school textbooks. The specific training tasks for every geometrical topic were, in general, to support and enhance the learning and training process in mathematics through a step-by-step solution, to guide the user to useful information, to provide opportunities for experimenting, and through the attractiveness of the whole product. The student trainees experimented through changing the values of the variables, through adding new GeoGebra elements or functions, as well as through adapting GeoGebra 
applets to other solutions or problems. Training the students for creating program codes for GeoGebra applets was also included in the training process.

The main tasks of every student involved: 1) finding one geometrical problem according to a pre-selected list of geometry topics with corresponding specific training tasks; 2) solving the geometrical problem with appropriate strategies and methods; 3) creating and integrating GeoGebra applets into the problem and solution on the basis of the specific training tasks; 4) presenting the final products created by the students before the other students in the group.

Diagnostic instruments. The evaluation of the creative characteristics of the product created by the student through quantitative measurements is irrational, which is why the study used a criteria test (Table $1 \div$

Table 6).

Table 1. Parameter: Solution of a geometrical problem

\begin{tabular}{lc}
\hline Indicator (I) & No \\
\hline Finds appropriate strategies and methods for solving the geometrical problem. & I1 \\
Uses mathematical facts, relations, and theories in logical sequence. & I2 \\
Transfers appropriate ideas, strategies, and methods from other mathematic fields & I3 \\
$\begin{array}{l}\text { or topics. } \\
\text { Produces a correct and complete solution of the problem. }\end{array}$ & I4 \\
\hline
\end{tabular}

Table 2. Parameter: Created GeoGebra applets

\begin{tabular}{lc}
\hline Indicator (I) & No \\
\hline Uses a wide variety of the GeoGebra options. & I5 \\
Builds new, unexpected links. & I6 \\
Develops attractive GeoGebra applets. & I7 \\
\hline
\end{tabular}

Table 3. Parameter: Integrated GeoGebra applets

\begin{tabular}{lc}
\hline Indicator (I) & No \\
\hline $\begin{array}{l}\text { Identifies appropriate GeoGebra elements, functions, methods, and links to the } \\
\text { solution of the assigned task. }\end{array}$ & I8 \\
Suggests new ways for visualising parts of the problem solution. & I9 \\
Applies in an innovative manner or identifies new spheres of application of the & I10 \\
GeoGebra applets, methods and settings. & \\
The combination of GeoGebra applets is suitable for the mathematical solution. & I11 \\
\hline
\end{tabular}


Table 4. Parameter: Qualities of the product

\begin{tabular}{lc}
\hline Indicator (I) & No \\
\hline The product has been created for a specific audience. & I12 \\
$\begin{array}{l}\text { The product fulfils specific training tasks and achieves the goal that has been set. } \\
\text { The product is new for the student who has created it, as well as for the target } \\
\text { audience. }\end{array}$ & I14 \\
$\begin{array}{l}\text { The student has invested a lot of knowledge, skills, previous experience, hard } \\
\text { work, and time in the creation of the training product. }\end{array}$ \\
$\begin{array}{l}\text { The product exceeds the knowledge taught in Mathematics and GeoGebra. } \\
\text { The product has an aesthetic and accurate layout. }\end{array}$ & I16 \\
The student suggests variants of the product. & I17 \\
\hline
\end{tabular}

Table 5. Parameter: Presentation of the product

\begin{tabular}{lc}
\hline Indicator $(\mathbf{I})$ & No \\
\hline $\begin{array}{l}\text { Presents the product clearly, in a logical sequence, using appropriate terms, } \\
\text { words, intonation, examples, comparisons, and interpretations. }\end{array}$ & I19
\end{tabular}

Table 6. Parameter: Interest and Satisfaction

\begin{tabular}{ll}
\hline Indicator (I) & No \\
\hline The student shares his/her satisfaction with the results achieved. & I20 \\
The audience demonstrates interest in the product presented by the student by & I21 \\
asking questions and making comments. &
\end{tabular}

The criteria test was filled out by every member of the training team (three experts in Geometry and GeoGebra) for every student's product. The students were acquainted with the criteria test in advance. The criteria test was a 5-level evaluation scale.

One student's result. The student Y. Taseva liked the geometry topic Rotation. She developed a WEB GeoGebra book with GeoGebra applets integrated into eleven geometrical problems (Figure 1, Figure 2). One of the problems chosen by her was as follows: A family bought a round table with a diameter of $150 \mathrm{~cm}$. The husband wondered whether there would be enough space for 12 chairs with dimensions $50 \mathrm{~cm}$ by $50 \mathrm{~cm}$, whereas the wife wondered whether she could put 12 plates with a diameter of 30 $\mathrm{cm}$ on the table, leaving enough space for the cutlery. The educational purposes of that problem were: 1) to use a dynamic GeoGebra environment; 2) to create a model of the problem and the solution which can be used for visualising the properties of the Rotation transformation. 

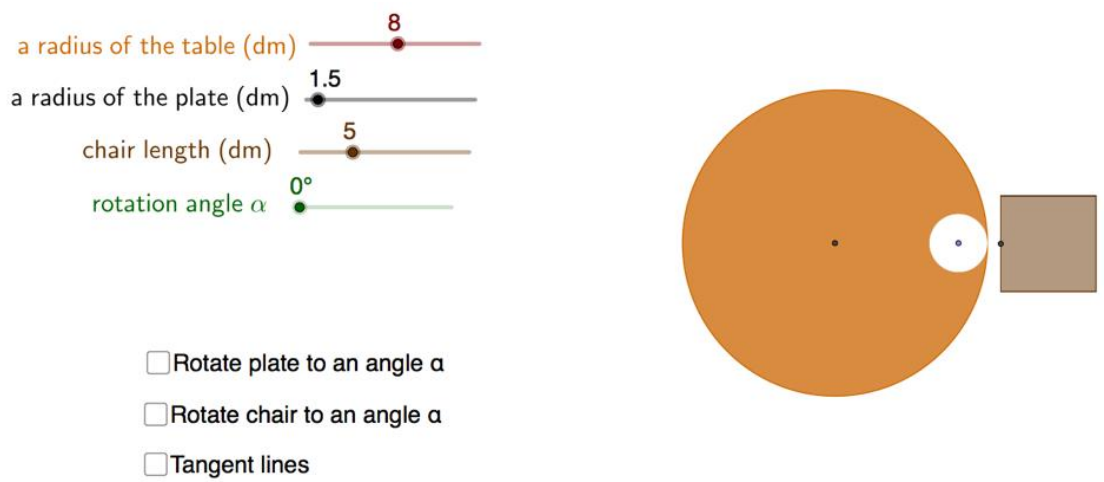

Figure 1. Integrated GeoGebra applet for visualising the Rotation transformation

The student Y. Taseva created and integrated applets which can be used to experiment with the radii of the table and the plates, the chair length, and the rotation angle. The model included Boolean functions, links between the various GeoGebra objects and functions. The problem was aesthetically visualized.
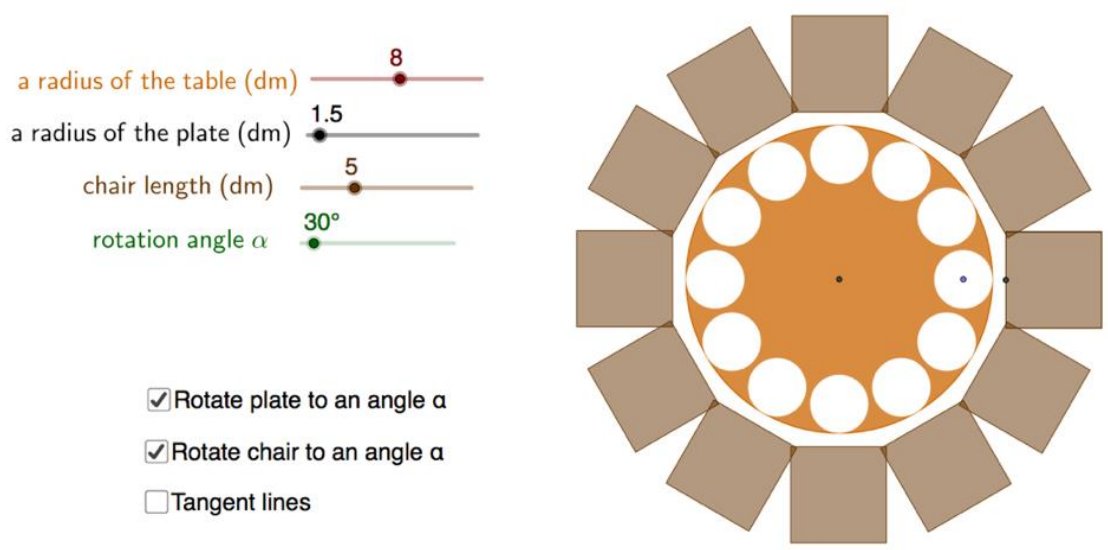

Figure 2. Manipulations with an Integrated GeoGebra applet

\section{Analysing the students' creativity}

The needs for educational innovations related to the development of technology, the significance of information, and the new lifestyle are reflected in the activities of the educational institutions aimed at creating new ways for fostering creativity and enhancing the teaching experience in the field of mathematics. By utilising the new information, digital, and non-digital technologies, they apply the principles of constructivism thus turning the educational settings into an environment which 
encourages the initiation of self-study by the trainees through the use of various instruments and materials aimed at identifying, designing, researching, experimenting, and creating educational products (Rendina, 2015). Another form of stimulating students' creativity is the educational coalition STEM (science, technology, engineering and mathematics), of recent times STEAM (A for "Arts"), called the maker movement, for the main purpose of gathering people for crafting, design and use of different kinds of technologies. The makerspaces may be useful to foster creativity and giftedness. They appeared in many schools in Canada as Brilliant Labs. These labs contribute development of digital competencies life-long continuum through instrumental usage, multiple interdisciplinary and transdisciplinary connections, among them, a collaborative problem-solving, creativity and innovation skills (Freiman et al, 2016). The maker movement aligns with the Schoolwide Enrichment Model of Renzulli and Reis (2014), which was applied successfully in a study of the stimulation of the mathematical creativity of talented high school students (Velikova, 2002). Therefore, the job-oriented preparation of teachers should encompass the formation of knowledge, skills, and competences for creativeness and for continuous search of interdisciplinary approaches to teaching and learning.

The training of the future teachers of mathematics and informatics aimed at developing teaching aids for teaching and learning mathematics through the use of the GeoGebra software options can be defined as successful, based on the evaluation of the creativity-oriented characteristics of the developed products. Since every product is a complex of many elements and reflects the personality characteristics of the student and of the activity which he or she performs, the research indicators (I) correspond: to the qualities of the mathematical solution of the chosen problem (Table 1); to the GeoGebra applets created (Table 2) and integrated into the solution (Table 3); to the final result as a whole (Table 4); to the presentation of the product before the target audience (Table 5); to the achievement of satisfaction by the creator and the interest aroused in the audience (Table 6).

The results in Figure 3 show that the students use in a logical sequence and successfully transfer relevant ideas, mathematical information, strategies, and methods from other mathematical fields or topics. The problem solutions are always correct and complete.

The values of 4.225, 4.500 of I5, I6, respectively (Figure 4), show that students create original applets, i.e. they create new, unexpected links between the GeoGebra elements. They pay a lot of attention to the creation of combinations of GeoGebra functions and to the attractiveness of the applets (4.250 of I7). Some students demonstrated superior skills in programming within a GeoGebra environment and created authoring functions or program codes. 


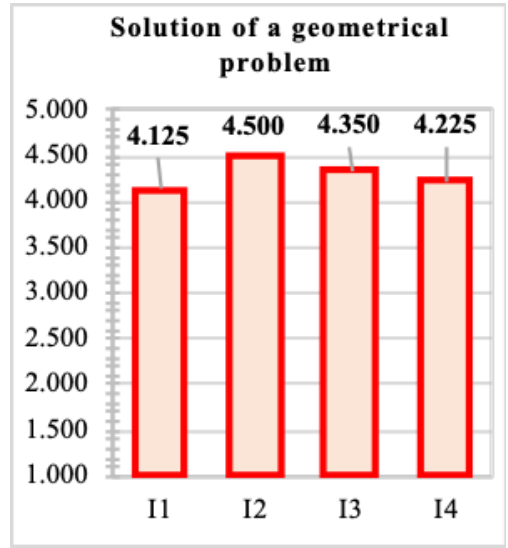

Figure 3.

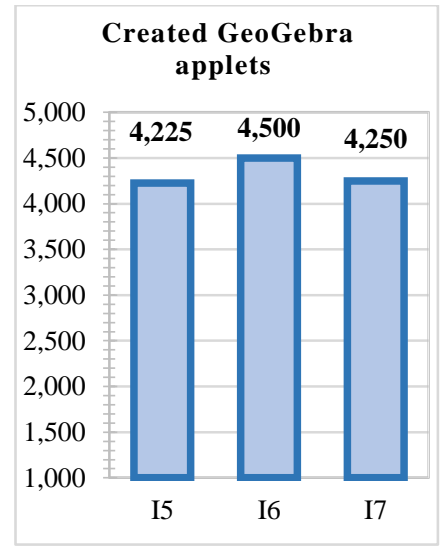

Figure 4.

The main idea of the technologically changing society is to create spaces with teaching aids which can be used by every teacher of mathematics at university or school level. That is why one of the main goals of the research was the acquisition of knowledge and skills for uniting the spheres of Mathematics and GeoGebra. The product received as a result of the appropriate integration of applets in the solution can be used for teaching or learning, for the purpose of achieving specific educational goals (Figure 5). The students showed a high level of creativity since the values of I9, I10 are, respectively, $4.225,4.500$, that is the students created new ways of visualising and new applications of the GeoGebra applets, methods, and settings, suitable for the mathematical solutions of the problems. Only few of the students used combinations of GeoGebra applets (4.000 of I11) since it is a very complicated process. Based on the findings of the experiment, we believe that this is the direction which can be followed for the purpose of creative teaching in other mathematical fields or topics.

Indicators $\mathrm{I} 12 \div \mathrm{I} 18($

Figure 6) are based on the definitions of creativity and students' creative product mentioned above. Creativity should be targeted at a specific audience, i.e. the knowledge used should be within the learning range of the students, in order to achieve specific educational goals and tasks.

Most of the products created by the students had the characteristics I12 and I13 (Figure 6). The implementation of the task performed by the student may not be novel from a scientific point of view. However, it is defined as creative if it is new to the student and the target audience. The creative aspects of the products were determined by the invested amount of knowledge, skills, previous experience, hard work, and time, which was confirmed by the high value -4.500 of I15. In several cases, it was identified that the evaluated products exceeded the knowledge taught in the fields of Mathematics and GeoGebra (value 3.225 of I16). The students strived to achieve an aesthetic and accurate layout of the final product variants (value 4.125 of I17). The students' skills for creating variants of the problem were developed to a lesser extent (value 3.500 of I18). 


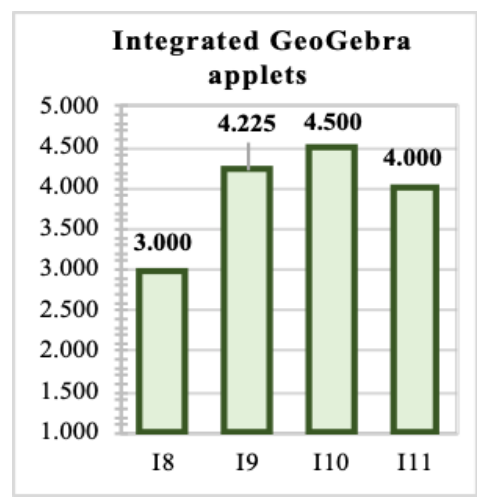

Figure 5.

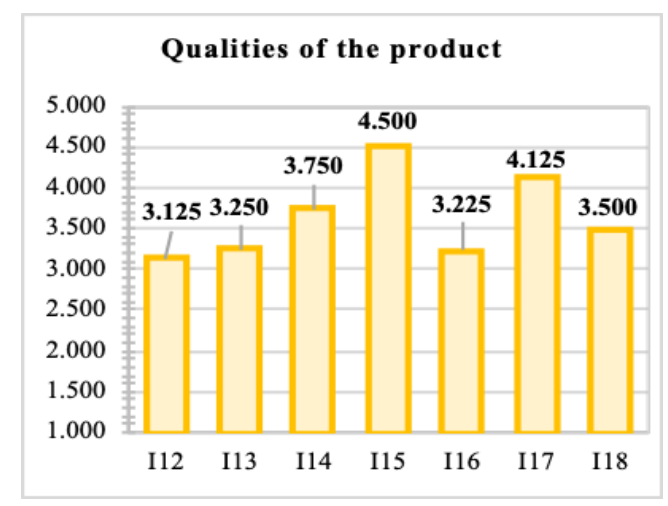

Figure 6.

An important aspect of the creative activities of the students was the presentation opportunity provided by the training team. Acquiring presentation skills is an important part of the job-oriented training of future teachers. The students feel the need to present the results of their work and these should be discussed with respect. Most of the students presented their products clearly, in a logical sequence, using appropriate terms, comparisons, examples, interpretations, words, and intonation (Figure 7).

All the students shared their satisfaction with the results achieved and with their participation in the creative training, as well as with the opportunities for presentation. The audience demonstrated an interest in the product that was presented (Figure 8).

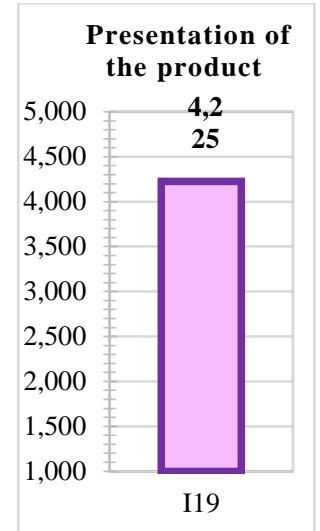

Figure 7.

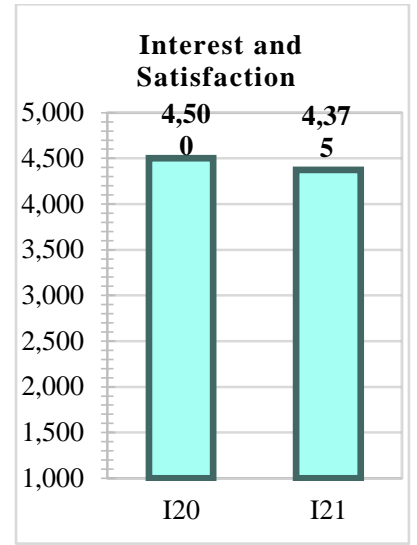

Figure 8.

The discussions, teamwork and individual work aimed at achieving high-quality results motivated the students to acquire new knowledge, skills and competences under the conditions of the creative mathematic GeoGebra environment. 


\section{Conclusions}

Every society needs talented professionals, creative people who design new technologies, future materials, and processes. The search for talented students and their training is a complicated task which should be fulfilled in schools at an early age. That is why the role of universities in identifying new technologies, models, methods, means, and forms of education for training highly qualified teachers for the educational labor market is extremely important.

This research was based on the investigation of the creative environment which supports students' creativity in developing and integrating GeoGebra applets for solving geometric problems in teaching and learning mathematics. The results show that this new educational technology which combines in a creative way mathematics and GeoGebra training is a successful environment for the job-oriented preparation of future Mathematics and Informatics teachers in high schools.

\section{References}

Aizikovitsh-Udi, E., Radakovic, N. (2012) Teaching probability by using geogebra dynamic tool and implemanting critical thinking skills/ Procedia - Social and Behavioral Sciences 46, $4943-4947$.

Bennevall, M. (2016). Cultivating Creativity in the Mathematics Classroom using Open-ended Tasks - A Systematic Review. Linköpings universitet, 26 p. Available at http://liu.diva-portal.org/smash/get/diva2:909145/FULLTEXT01.pdf

Bilbao, J., Bravo, E., Garcia, O. (2017). Assesment of Computational Thinking Notions in Secondary School, Baltic J. Modern Computing, Vol. 5, No. 4, 391-397.

Cachia, R., Ferrari, A., Ala-Mutka, K., Punie, Y. (2010). Creative learning and innovative teaching: Final Report on the Study on Creativity and Innovation in Education in EU Member States.

Desev, L. (1999). Dictionary in Psychology /more than 2000 terminus/ Fourth Edition, S. Bulgarika.

Freiman, V., Tassel, J.L. (2018). Creativity and Technology in Mathematics Education. VII, 561 p. Mathematics Education in the Digital Era, Vol. 10. Springer International Publishing.

Freiman, V., Larose, F., Chukalovskyy, R., LeBlanc, M., Léger, M., Bourgeois, Y., Godin, J. (2016). Defining and Developing Life-long Digital Competences: Partnership Building Approach. In: Proceedings of the EDULEARN 2016 IC, 4-7 July, Barcelona, Spain.

Georgieva, M. (2001). The Reflection in the mathematics training (V-VI class), V. Tarnovo, Freber, $199 \mathrm{p}$.

Haciomeroglu, E.S. (2011). Visualization through dynamic GeoGebra illustrations. In Bu, L. \& Schoen, R. (Eds.), Model-centered Learning Pathways to Mathematical Understanding Using GeoGebra (pp. 133-144), The Netherlands: Sense Publishers.

Hohenwarter, J., Hohenwarter, M., Lavicza, Z. (2009). Introducing Dynamic Mathematics Software to Secondary School Teachers: the Case of GeoGebra. Journal of Computers in Mathematics and Science Teaching, 28(2), 135-146. Waynesville, NC USA: Association for the Advancement of Computing in Education (AACE). Retrieved August 18, 2019. Available at https://www.learntechlib.org/primary/p/30304/

Kim, K.M., Md-Ali, R. (2017). GeoGebra: Towards Realizing 21st Century Learning in Mathematics Education. Malaysian Journal of Learning and Instruction: Special Issues 2017: 93-11593.

Kritetskii, V. (1968) The Psychology of mathematical abilities in school child, M., Procvestenie. 
Kubilinskiene, S., Zilinskiene, I., Dagiene, V., Sinkevicius, V. (2016). Baltic J. Modern Computing, Vol. 5, No. 1, 50-69.

Liljedahl, P., Sriraman, B. (2006). Musings on mathematical creativity, For The Learning of Mathematics 26(1), 20-23.

Martinovic, D., Manizade, A. (2014). Technology as a Partner in the Geometry Classroom. The Electronic Journal of Mathematics and Technology. Vol. 8.

Olsson, J. (2017). GeoGebra, Enhancing Creative Mathematical Reasoning. PhD Thesis, Dalarna University, School of Education, Health and Social Studies, Mathematics Education, 52 p.

Or, A. C. M. (2013). Designing Tasks to Foster Operative Apprehension for Visualization and Reasoning in Dynamic Geometry Environment, Task Design in Mathematics Education. Margolinas, C. (Ed.), Proceedings of ICMI Study 22. Oxford, pp. 89 - 98.

Petkova, M. (2011). Teaching and Learning Mathematics Based on GeoGebra Usage. In: Proceedings of the Union of Scientists - Ruse, Book 5 - Mathematics, Informatics and Physics, Vol. 8, $145-152$.

Petkova, M. (2016). Pedagogical technologies for integrating GeoGebra applications into geometry education. PhD Thesis, University of Ruse, Bulgaria, $247 \mathrm{p}$.

Petkova, M., Velikova, E. (2015a). GeoGebra Constructions and Problems for Arbelos and Archimedean circles. GeoGebra Global Gathering, 15-17 July, 2015, International GeoGebra Institute, Linz, Austria.

Available at http://tube.geogebra.org/material/simple/id/1383213

Petkova, M., Velikova, E. (2015b). Mathematical Problem Posing on the Basis of the GeoGebra Multi-platform, in Proceedings of the Annual Conference RU \& SU, 09-10.10.2015, 70 years of traditions and innovations, 54, (6.4), pp. 28-39.

Rendina, D. (2015). Defining makerspaces: What research says? Available at http://renovatedlearning.com/2015/04/02/defining-makerspaces-part-1/

Renzulli, J. S., Reis, S. M. (2014). The schoolwide enrichment model: A how-to guide for talent development (3rd ed.). Waco, TX: Prufrock Press.

Sternberg, R., Lubart, T. (1999) The concept of creativity: Prospects and paradigm, (R. Sternberg, Ed.) Handbook of creativity, 3-16, N.Y.: Cambridge University Press.

Velikova, E. (2002). Stimulating the mathematical creativity of students (9-12 class) Dissertation thesis, University of Veliko Tarnovo, Bulgaria, 2002, 369 p.

Velikova, E. (2008). Promoting creativity for all students - educational technology and multimedia usage, Proceedings of the DG9, 11 International Congress on Mathematical Education, 2008, Mexico, Published by the University of Rousse and the University of Latvia, p. 330-344.

Zilinskiene, I., Demirbilek, M. (2015). Use of GeoGebra in Primary Math Education in Lithuania: An Exploratory Study from Teachers' Perspective. Informatics in Education.

WEB (a). European Parliament and the Council for developing eight Key Competences. Available at https://ec.europa.eu/education/policy/school/competences_en

WEB (b). GeoGebra. Available at https://www.geogebra.org/about?ggbLang=en

WEB (c). GeoGebra Institute of Ruse (GGIR). Available at http://ggir. uni-ruse.bg/ 